\title{
Ecological Efficiency Analysis in Zhejiang Province: Based on Improved Super-SBM Model
}

\author{
Zeyuan $\mathrm{Zhu}^{1,}{ }^{*}$, Sizhan $\mathrm{Liu}^{2}$ \\ ${ }^{1}$ Business School, Hohai University, Changzhou 213022, China; \\ ${ }^{2}$ College of Mechanical and Electrical Engineering, Hohai University, Changzhou 213022, China;
}

\begin{abstract}
This paper use the super efficiency SBM-DEA model with undesirable outputs to calculate the ecological efficiency of Zhejiang Province from 2001 to 2018, and construct multiple linear regression model that evaluating the influencing factors of ecological efficiency based on it. The ecological efficiency of Zhejiang Province fluctuated and increased during the study period, which was mainly driven by pure technical efficiency. In the multiple regression analysis, it can be concluded that income factors, structural factors and institutional factors have a gradually weakening positive impact on ecological efficiency. This paper argues that Zhejiang Province should make full use of regional advantages, resource advantages and talent advantages on the basis of maintaining the current industrial level. It is advised to vigorously develop high-tech industries, strengthen international communications on knowledge and seek new economic growth points. Finally a higher level of coordination between economic development and ecological protection can be achieved.
\end{abstract}

\section{Introduction}

After China's reform and opening up, the economy has developed rapidly. At the same time, the contradiction between economy and environment has gradually become prominent, and the reform and opening up has entered a deep water zone. Zhejiang Province, located in the core area of the Yangtze River Delta Economic Circle, is the first batch of pilot provinces for ecological construction in China, and its ecological achievements have been in the forefront of the country for many years. In 2019, the forest coverage rate of Zhejiang Province reached $59.4 \%$, ranking fourth in the country. Throughout the past few years, Zhejiang Province has contributed $6.9 \%$ of GDP to $3.9 \%$ of the country ' $\mathrm{s}$ resource consumption, which fully shows its excellent effect of promoting ecological construction while maintaining high economic benefits.

The concept of eco-efficiency was first proposed by Schaltegger [1], a German scholar in 1990, which discussed the relationship between economic value generated by economic activities and environmental pollution. Many foreign scholars have studied ecological efficiency from multiple perspectives [2]. Domestic scholars have also measured and evaluated the ecological efficiency from the perspectives of different fields, such as cities [3], rural areas, and geographical locations, such as the Yangtze River Economic Belt [4]. Analytic Hierarchy Process, Fuzzy Comprehensive Evaluation and Data Envelopment Analysis are the main evaluation methods of ecological efficiency [5]. Among them, the data envelopment analysis (DEA) is adopted by many scholars because it can be used for input-output under various conditions and is not subject to the constraints of index dimension. Zhao Kangjie [6] used Malmquist-Luenberger index to analyze the ecological efficiency of the Yellow River Basin, and found that increasing per capita GDP was the most obvious improvement in ecological efficiency. Based on the measurement of ecological efficiency, the correlation regression analysis can further study the influencing factors of ecological efficiency.

This paper selects reasonable input-output indicators to measure the ecological efficiency of Zhejiang Province from 2001 to 2018, and through fitting relevant influencing factors, regression analysis is conducted on the contribution degree of influence, and finally corresponding countermeasures and suggestions are put forward. The research on ecological efficiency and its influencing factors is conducive to improving the level of ecological efficiency more efficiently and promoting the coordinated development of regional economy and ecological environment.

\section{Research methods and data sources}

\subsection{Construction of ecological efficiency}

DEA model is a statistical estimation method of nonparametric analysis, which can realize the evaluation of multi-input and multi-output. To overcome the shortcomings of ordinary DEA model, Tone [7] proposed SBM-DEA (Slack Based Efficiency-DEA)

* Corresponding author: zzy2018@hhu.edu.cn 
model to solve the problem of variable relaxation and super efficiency SBM model to implement more effective measurement. Environmental pollution will cause the loss of ecological efficiency, and this model can effectively solve the problem of ecological efficiency evaluation undesirable outputs. Therefore, this paper uses the input-oriented super-efficiency SBM model with undesirable outputs to measure the ecological efficiency of Zhejiang Province from 2001 to 2018. The model is as follows:

$$
\begin{aligned}
& \min \rho_{\mathrm{SE}}=1+\frac{1}{\mathrm{~m}} \sum_{i=1}^{\mathrm{m}} s_{i}^{-} / x_{i k} \\
& \text { s.t. }\left\{\begin{array}{l}
\sum_{j=1, j \neq k}^{n} x_{i j} \lambda_{j}-s_{i}^{-}, x_{i k} \\
\sum_{j=1, j \neq k}^{n} y_{r j} \lambda_{j}, . y_{r k}
\end{array}\right.
\end{aligned}
$$

In the formula, $\lambda, s^{-} \geq 0 ; i=1,2, \ldots, \mathrm{m} ; r=1,2, \ldots, \mathrm{q}$; $j=1,2, \ldots, \mathrm{n}(\mathrm{j} \neq \mathrm{k}) . x_{i j}$ is the input of the $j$ decision unit for type $i, y_{r j}$ is the output of the $j$ decision unit for type $r, s^{-}$is the relaxation variable.

Based on CCR model with constant returns to scale and BCC model with variable returns to scale, the technical efficiency (TE) and pure technical efficiency (PTE) of the evaluated object can be obtained respectively, and then the scale efficiency (SE) of the evaluated object can be obtained by the formula ' TE / $\mathrm{PTE}=\mathrm{SE}^{\prime}$.

\subsection{Measurement of industrial structure}

The theory of industrial structure upgrading is mainly manifested in two aspects. One is the change in the proportion of the three major industries, and the second is the improvement of labor productivity each industry. Some scholars use the proportion of various industries to reflect the height of the industrial structure, such as Gan Chunhui [8] based on Clark' s law with the second and third industry output value ratio as a measure of the height of the industrial structure. In order to reduce the multicollinearity of the model, this paper draws on the practice of Gan Chunhui, selects the proportion of the second and third output value as the index of industrial structure, which can eliminate the influence of the absolute growth of productivity on the index of industrial structure.

\subsection{OLS multiple linear regression model}

According to the perspective of relevant scholars, this paper will start from income factors, structural factors and institutional factors to construct the OLS time series multivariate linear regression model of ecological efficiency in Zhejiang Province. The income factor is expressed by regional per capita GDP; Structural factors are expressed by the indicators of industrial structure upgrading calculated above; In institutional factors, environmental regulation is the main input, and the total investment in regional environmental governance is selected in this paper. The model is set as follows:

$$
\begin{aligned}
& E C O_{t}=\alpha_{0}+\beta_{1} L Y_{t}+\beta_{2} T S_{t}+\beta_{3} R E G_{t}+\mu_{t} \\
& Q=\sum_{i=1}^{n} e_{i}^{2}=\sum_{i=1}^{n}\left(E C O_{i}-E \hat{C} O_{i}\right)^{2} \\
& \quad=\sum_{i=1}^{n}\left[E C O_{i}-\left(\hat{\alpha}_{0}+\hat{\beta}_{1} L Y_{t}+\hat{\beta}_{2} T S_{t}+\hat{\beta}_{3} R E G_{t}\right)\right]^{2}
\end{aligned}
$$

$t$ denotes time, ECO denotes the value of ecological efficiency, $L Y$ denotes GDP per capita, TS denotes the measurement index of industrial structure upgrading, $R E G$ denotes the measurement index of environmental regulation, and $\mu$ denotes the random error term.

\subsection{Index selection and data source}

In the calculation of ecological efficiency, the capital index is estimated by the method of continuous inventory [9], and the remaining indicators are shown in the Table 1 .

Table 1. Ecological efficiency index composition

\begin{tabular}{ccc}
\hline Type & Name & Index \\
\hline \multirow{2}{*}{ Input } & Water use & $\begin{array}{c}\text { Total water use } \\
\text { Standard coal } \\
\text { consumption }\end{array}$ \\
& Land consumption & Agricultural acreage \\
& Capital input & Stock of capital \\
& Luabor input & emplity of \\
& Desirable output & Regional GDP \\
\hline \multirow{2}{*}{ Output } & Undesirable output & $\mathrm{CO}_{2}, \mathrm{SO}_{2}$ \\
& COD, $\mathrm{Ammonia-N}$ & \\
\hline
\end{tabular}

This paper selects the relevant data of Zhejiang Province from 2001 to 2018. The data are derived from the National Bureau of Statistics, China Statistical Yearbook, China Energy Statistics Yearbook and Zhejiang Statistical Yearbook of Natural Resources and Environment.

\section{Result analysis}

\subsection{Ecological efficiency analysis}

Based on the above relevant input and output indicators, the ecological efficiency related indicators of Zhejiang Province from 2001 to 2018 are calculated, including technical efficiency value, pure technical efficiency value, scale efficiency and change direction. On the basis of the results, the evolution trend diagram of ecological efficiency in Zhejiang Province from 2001 to 2018 is drawn, and the results are shown in Figure 1. 


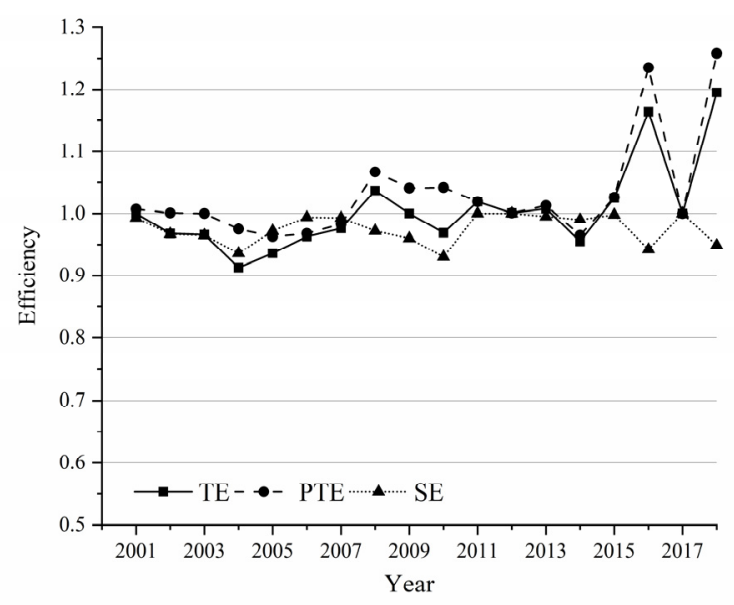

Fig. 1. Evolvement trend of ecological efficiency in Zhejiang Province from 2001 to 2018

It can be seen from this figure that the overall level of ecological efficiency in Zhejiang Province showed a fluctuating upward trend during the study period. In 2004, the ecological efficiency level reached the lowest point, and the technical efficiency was 0.913 . After this year, the pure technical efficiency increased rapidly, and reached a regional peak at 1.067 in 2008. Due to the limited field of input factors, there will be no large changes in the short term, so the scale efficiency is relatively stable and has a certain lag effect. From 2010 to 2015 , the indicators of ecological efficiency were relatively stable. In 2016 and 2018, the pure technical efficiency reached a high value of 1.235 and 1.258, respectively. It can be seen that the ecological efficiency of Zhejiang Province has developed well in recent years.

\subsection{Correlation analysis}

By calculating the data of relevant factors affecting regional ecological efficiency, including revenue factor $(L Y)$, structural factor $(T S)$ and institutional factor $(R E G)$, Fig. 2 is drawn as follows:

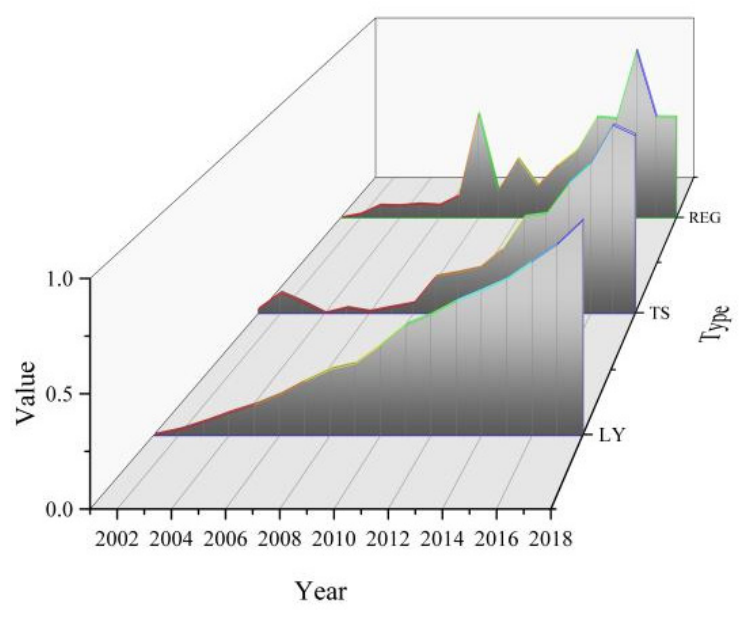

Fig. 2. Trend of income, structural and institutional factors in Zhejiang from 2001 to 2018
It can be seen from the above figure that the development trend of the three influencing factors is characteristic. The average income $L Y$ basically showed a linear growth trend, which is more stable. Industrial structure height $T S$ developed slowly before 2008, but grew rapidly afterwards. The total amount of environmental governance investment $R E G$ has increased rapidly in general, and has also increased significantly since 2008. In 2011, Zhejiang Province issued " '811' Promoting Action Programme for Ecological Civilization Construction. " Total investment in environmental governance rose steadily from 2011 to 2016. In 2016, Zhejiang opened a new round of '811' special action, introducing the concept of ' building a beautiful Zhejiang and creating a better life '. At the same time, the total investment in environmental governance reached its peak in that year. Among them, $E C O$ has a strong positive correlation with $L Y$ and $R E G$, which are 0.584 and 0.688 respectively, which are both significant in the single-tail test. The correlation with structural factors $T S$ is weak: 0.100 . Income factors have weak correlation with structural factors and strong correlation with institutional factors.

\subsection{OLS multiple regression analysis}

\subsubsection{Stationary test}

The stationary test can be judged by unit root test of each time series data to avoid the occurrence of pseudo regression in time series regression. In order to improve the accuracy of stationary test results, this paper will use two test methods, including ADF-Fisher and PP-Fisher test. The test results are shown in Table 2. ( $\triangle$ means first-order difference, $\Delta^{2}$ means second-order difference )

Table 2. Stationary test results

\begin{tabular}{cccc}
\hline Variable & ADF-Fisher & PP-Fisher & Result \\
\hline$E C O$ & 0.024 & 0.024 & Stable \\
$L Y$ & 0.971 & 0.942 & Unstable \\
$T S$ & 0.673 & 0.289 & Unstable \\
$R E G$ & 0.021 & 0.021 & Unstable \\
$\triangle L Y$ & 0.122 & 0.122 & Unstable \\
$\triangle T S$ & 0.025 & 0.000 & Stable \\
$\triangle R E G$ & 0.000 & 0.000 & Stable \\
$\triangle^{2} L Y$ & 0.023 & 0.000 & Stable \\
\hline
\end{tabular}

The ADF test $\mathrm{t}$ of $E C O$ is -4.128 , which is less than 3.710 at $5 \%$ level. $L Y$ is still a non-stationary sequence after the first-order difference, and then the second-order difference satisfies. Both $T S$ and $R E G$ pass the stationarity test in the first-order difference. It is proved that all variables are stable, and there is no false regression phenomenon in regression analysis, so regression analysis can be carried out. 


\subsubsection{Model fitting regression analysis}

Table 3 provides information about regression fitting. The coefficient of income factor $L Y$ in the model is 0.607 , and the relative influencing factors are larger. The $T S$ coefficient of structural factor is 0.227 , and the $R E G$ coefficient of institutional factor is 0.149 , and the constant is 0.928 . At the significant level, $R E G$ was more significant. Three variance expansion factor VIF are $1.641,1.239,1.904$, indicating that the three multicollinearity is weak.

Table 3. Correlation coefficient regression results

\begin{tabular}{|c|c|c|c|c|c|c|}
\hline \multirow{3}{*}{ Model } & \multicolumn{3}{|c|}{ Unstandardized } & \multirow{3}{*}{ Significance } & \multirow{2}{*}{\multicolumn{2}{|c|}{ Colinearity }} \\
\hline & Coe & fficients & $\mathrm{t}$ & & & \\
\hline & $\mathrm{B}$ & STDERR & & & Tolerance & VIF \\
\hline$C$ & 0.928 & 0.030 & 30.681 & 0.000 & 1 & I \\
\hline$L Y$ & 0.607 & 0.604 & 1.005 & 0.332 & 0.609 & 1.641 \\
\hline$T S$ & 0.227 & 0.349 & 0.649 & 0.527 & 0.807 & 1.239 \\
\hline$R E G$ & 0.149 & 0.063 & 2.381 & 0.032 & 0.525 & 1.904 \\
\hline
\end{tabular}

Through further analysis, the value of $\mathrm{R}^{2}$ is 0.536 , indicating that $53.6 \%$ of the change of ecological efficiency value can be explained by $L Y, T S$ and $R E G$. At $5 \%$ significance level, the critical value of $F$ statistic is $\mathrm{F}_{0.05}(3,18)=3.16$, which is less than $\mathrm{F}$ value, indicating that the linear relationship is significant. In addition, the $\mathrm{D}$.W. value is 1.928 , close to 2 , indicating that there is no first-order autocorrelation.

\section{Conclusions and discussion}

From the above analysis, it can be seen that the ecological efficiency of Zhejiang Province has an obvious upward trend from 2004 to 2008 and 2014 to 2018. Higher levels of industrial structure grew slowly before 2008, but increased rapidly afterwards. Environmental governance investment peaked in 2008 and 2016, and increased steadily after 2011. In the regression analysis of the impact of ecological efficiency, the strongest impact is the economic factors represented by income, followed by the industrial structure, and then the related institutional investment factors.

In order to promote the improvement of ecological efficiency and enhance the sustainable development ability of China ' $s$ economy, this paper puts forward the following suggestions based on the above conclusions:

(1) Pay attention to the steady improvement of industrial structure, taking the advancement and rationalization into account simultaneously. In this study, the critical point of industrial structure upgrading in Zhejiang Province is in 2008, after that it has maintained a high growth rate. But behind this is easy to promote unbalanced, irregular industrial transformation. Such as the transformation of agricultural productivity into highpolluting and high-emission industries, or the addition of low-quality services. Therefore, we should strengthen the rationality of construction while promoting the transformation of industrial structure.
(2) Promote the implementation of ecological protection system, increase investment in pollution control. The effective implementation of the regulatory system is conducive to the flow of capital and other production factors to environmental protection and energy-saving enterprises. The gradual elimination or upgrading of enterprises with low ecological benefits will also promote regional sustainable development.

(3) Improve science and technology innovation ability, seek new growth chance of economic development. In recent years, high-tech industries such as IT industry represented by Alibaba have developed rapidly in Zhejiang Province, and traditional manufacturing enterprises such as Geely and Wanxiang are also constantly upgrading. The government should promote the agglomeration of small and medium-sized enterprises, create a diversified supply chain, promote industrial complementary advantages and scale efficiency, and improve core competitiveness.

\section{References}

1. Schaltegger S., Sturm A. (1990) Ökologische rationalität: Ansatzpukte zur ausgetsaltung von ökologieorientierten managementinstrumenten. Die Unternehmung, 44(4): 273-290.

2. Belucio, M., Rodrigues, C., Antunes, C., Henggeler et al. (2021) Eco-efficiency in early design decisions: A multimethodology approach. Journal of Cleaner Production, 283.

3. Yang, Y. and Deng, X., (2019) The spatial and temporal evolution of urban ecological efficiency and regional differences in influencing factors in China. Geography, 39 (07): 1111-1118.

4. Wang Z., Liu Q., (2019) The spatial and temporal evolution of tourism ecological efficiency and its interaction with tourism economy in the Yangtze River Economic Belt. Journal of Natural Resources, 34 (09): 1945-1961.

5. Tan L. et al., (2010) Comprehensive evaluation method of ecological efficiency. Pollution control technology, (04): 5-9.

6. Zhao K., Liu X., (2020) The Yellow River Basin water-energy composite ecological efficiency evaluation and influencing factors: Compared with the Yangtze River Economic Belt. Coal economy research, 40 (08): 28-35.

7. Tone K.A. (2002) Slacks-based measure of superefficiency in data envelopment analysis. European Journal of Operational Research, 143(1): 32-19.

8. Gan C., Zheng R. and Yu F., (2011) The impact of China's industrial structure change on economic growth and volatility. Economic research, 46 (05): 4-16.

9. Chen C., (2014) Variable depreciation rate estimation and capital stock calculation. Economic research, 49 (12): 72-85. 